\title{
Study on Optimum Structural Design of Roller Bit Bearing Double Rubber Ring Seal
}

\author{
Yi Zhou ${ }^{1}$, Lin Wang ${ }^{2}$ \\ School of Mechatronic Engineering, Southwest Petroleum University, Chengdu, 610500, China
}

\begin{abstract}
Roller bit is one of the most important rock-breaking tool in drilling engineering, Its performance will directly affect the quality of drilling, drilling efficiency and drilling cost; Bit life depends on the bearing life, And the bearing life is largely dependent on the bearing seal life. In this paper, By using the nonlinear finite element software ABAQUS to establish the 2D axisymmetric model of cone bit double rubber ring seal, Simulate the assembly process and external pressure of roller bit, Analysis and calculation for different inner pore structure of rubber ring strain, compression ratio and contact pressure distribution; Analysis and calculated for different shaft diameter groove structure on the sealing surface of the strain, the compression rate and the impact of the contact pressure; Analysis and calculated for different cross-sectional shape of the rubber ring strain, compression ratio and the contact pressure distribution; The results showed: Straight cone bore conducive to two rubber ring equal life. The rectangular groove structure is beneficial to reduce the strain, compression rate and maximum contact pressure of rubber ring. When the double-notch fillet radius 0.5 , the rubber ring has a minimal strain, compression rate, contact pressure. $O$-section rubber ring is better than other cross section rubber ring.
\end{abstract}

Keywords: Double rubber ring seal; Straight cone bore; Groove structure; Section shape

\section{Introduction}

According to the field statistics show: The failure of the drill bit which is caused by the early failure of the bearing is $80 \%$ of the total number of the drill bit. The serious wear and tear of the bearings due to the early sealing failure is $30 \%$ of the total number of failure bearings ${ }^{[1]}$. Therefore, The sealing performance is one of the main factors that affect the working life of the drill bit. And the entry of mud solid is the main factor leading to the failure of bearing seal. Mud solid into the bearing, Resulting in increased bearing wear, Early damage. The main bearing seal of cone bit at home and abroad are three forms of sealing: Rubber ring seal, hydrodynamic seal, metal floating seal. Rubber ring seal is the most commonly used way of sealing, it has the advantages of simple structure, easy fabrication, convenient disconnection, low cost, etc, and is widely used in the fields of machinery, petroleum industry, aviation and spaceflight, etc.

A lot of research on the rubber ring seal has been made at home and abroad ${ }^{[2-4]}$. But few research on the double rubber ring, Domestic Fafen Xing in 2012 for the first time put forward the double rubber ring seal, And apply for the invention patent: roller bit bearing double rubber ring sealing system ${ }^{[5]}$. The double rubber ring sealing system comprises two sealing rings, the main seal and the secondary seal to protect primary seals. Since the structure has been proposed, The research on sealing system has not been reported. In this paper, by launching cone bit bearing double rubber ring seal structure optimization, Find the best sealing structure, In order to further improve the sealing structure, improve service life and provide a theoretical basis for roller bit, So as to guide the design.

\section{Double rubber ring sealing structure}
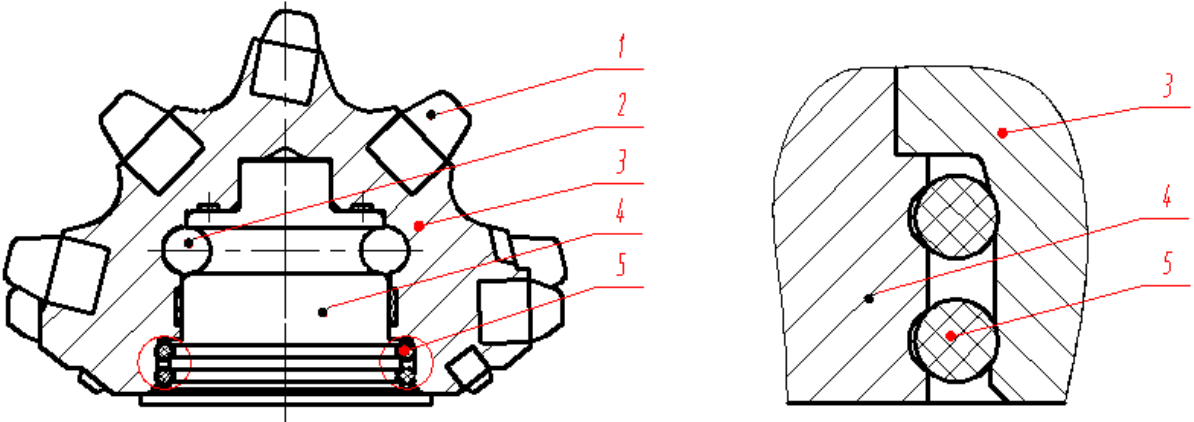

(a) Bit double seal assembly drawing; (b) Sealing parts of partial enlargement;

Figure 1: Structure of roller bit bearing double rubber ring seal.

1-teeth; 2 - Ball; 3 - roller; 4 - bearing; 5- rubber ring;

Figure 1 is the structure chart of roller bit bearing double rubber ring seal, Which (a) is the assembly drawing of roller bit bearing double sealing rubber ring, (b) is the partial enlargement of seal parts. Double rubber ring seal structure 


\section{International Journal of Science and Research (IJSR) \\ ISSN (Online): 2319-7064 \\ Index Copernicus Value (2013): 6.14 | Impact Factor (2015): 6.391}

is composed of a pair of $\mathrm{O}$ type high elastic rubber ring, roller and a bearing. Its operating principle is: the sealing area two high elastic $\mathrm{O}$ type rubber ring is positioned on the bearing journal and cone bore, Two $\mathrm{O}$ type rubber ring under pressure to provide reliable sealing pressure, to ensure the rubber ring and the bearing journal and cone hole to maintain contact well, and radial seal. Double rubber ring seal by two rubber ring seal, Outer seal to prevent the abrasive grain in the drilling fluid into the sealed cavity, and the inner sealing to prevent the lubricating oil leakage, prevent bearing contact with drilling fluid, two rubber ring sealing performance is greatly improved, thus greatly improved the service life of the bearing.

\section{Simulation Analysis}

Conduct simulation analysis of the different shaft neck groove structure, rock pore structure, study different slot structure, the cone inner pore structure influence on the sealing performance, find the optimal sealing structure, guide the new-type sealing structure design provides a theoretical basis.

\subsection{Finite element model}

\subsubsection{Gometric model}

Due to the structure with axial symmetry, $1 / 2$ model were analyzed, and bearing journal and the rigidity of cone hole far compared with type $\mathrm{O}$ rubber ring, ignore the deformation of the bearing journal and cone hole, only the contour lines represent the two rubber ring, cone bore geometrical model was created when a large bearing journal just touching.

\subsubsection{Defining materials}

O type is nitrile butadiene rubber material that is used by the rubber ring due to the rubber material is nonlinear, ultra incompressible elastic body, its mechanical performance for complex material nonlinearity and geometrical nonlinearity, Characterized by the domestic and foreign scholars generally the Mooney - Rivlin model strain energy functions of rubber material, its function can be expressed as: $W=C_{01}\left(I_{1}-3\right)+C_{02}\left(I_{2}-3\right), \mathrm{W}$ for the strain energy density; $C_{01}, C_{02}$ for Mooney constants of materials; $I_{1}, I_{2}$ for the first and second strain tensor invariant; In this paper, $C_{01}, C_{02}$ were $1.87,0.47[6]$.

\subsubsection{Define contact}

Because bearing journal and the cone hole is defined as a rigid surface, they contact with two rubber ring belongs to soft contact, a total of four pairs of contact. For solving contact problem has a solution based on the direct constraint method, the Lagrange multiplier method and penalty function method. Because of the dual structure of sealing rubber ring contact belongs to large deformation, material nonlinearity of contact problem, and there the geometric nonlinearity, material nonlinearity and boundary nonlinearity, the domestic and foreign scholars generally can be solved by using the penalty function method, and adopts the contact area penalty function method was applied to discuss the design parameters, define the friction factor of 0.5 .

\subsubsection{Applied load}

Use move along the radial bearing, cone along the radial, axial moving method to simulate the assembly process. To exert pressure difference inside and outside its working process simulation.

\subsubsection{Meshing}

Using free meshing for two rubber ring as a whole, number of 60 units, unit shape of the tetrahedron grid unit, when calculating the triangular unit stable and reliable.Eventually establish finite element model as shown in figure 2.

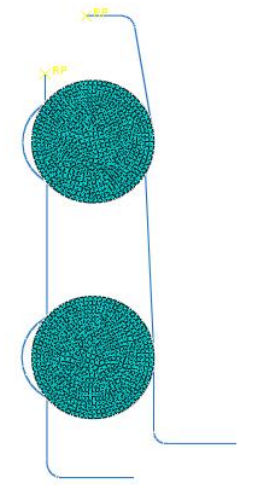

Figure 2: Prototype structure finite element model

\subsubsection{Results}

The prototype structure simulation analysis:

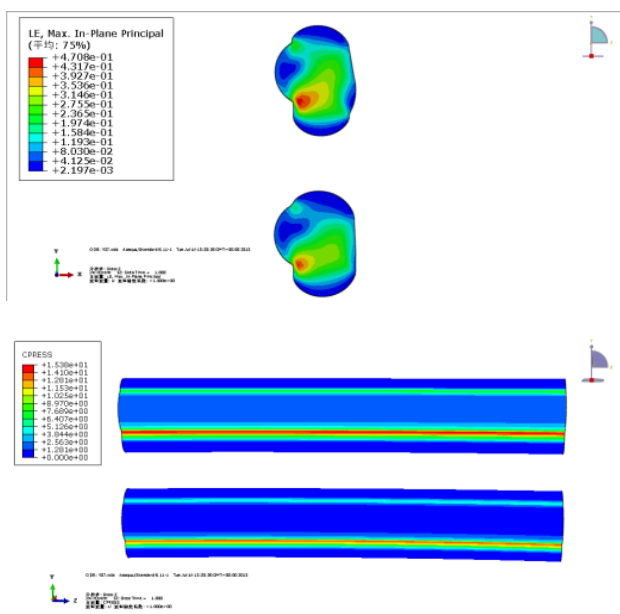

(a) Strain diagram (b) Contact pressure diagram

Figure 3: Prototype structure simulation results of rubber ring

The results showed that: (1) The cone hole of back support structure leads to different top and bottom rubber ring of the uneven distribution of strain. Top rubber ring appears on the maximum strain area is bigger than the bottom, indicating failure of the rubber ring on the bottom rubber ring is more serious, this is determined by the rubber ring on the back support structure. (2) Contact pressure distribution of upper and lower rubber ring, rubber ring on the seal pressure is greater than the rubber ring seal pressure value. Two synthetic sealing pressure maximum sealing pressure is greater than normal work requirements, (as shown in figure 


\section{International Journal of Science and Research (IJSR) \\ ISSN (Online): 2319-7064 \\ Index Copernicus Value (2013): 6.14 | Impact Factor (2015): 6.391}

$3 \mathrm{~b}$ ). Its value is $15.38 \mathrm{Mpa}$, and drill bit bearing seal pressure for 5-6 Mpa commonly can ensure the reliability of the seal. Excessive seal pressure rubber ring to excessive compression rate to provide the required sealing pressure for sealing surface, greatly affecting the performance of the rubber ring to reduce its flexibility and aging resistance, and thus the service life of the rubber ring. (3) The top rubber ring on the compression ratio is $25.01 \%$, the bottom rubber ring compression rate is $21.74 \%$, the compression ratio of two rubber ring for not less than $10 \%-15 \%$ of the normal work of the rubber ring.

\section{Structure Optimization}

\subsection{The inner hole of the back support structure improvement}

Change the cone inner hole of the back support structure into a linear type.
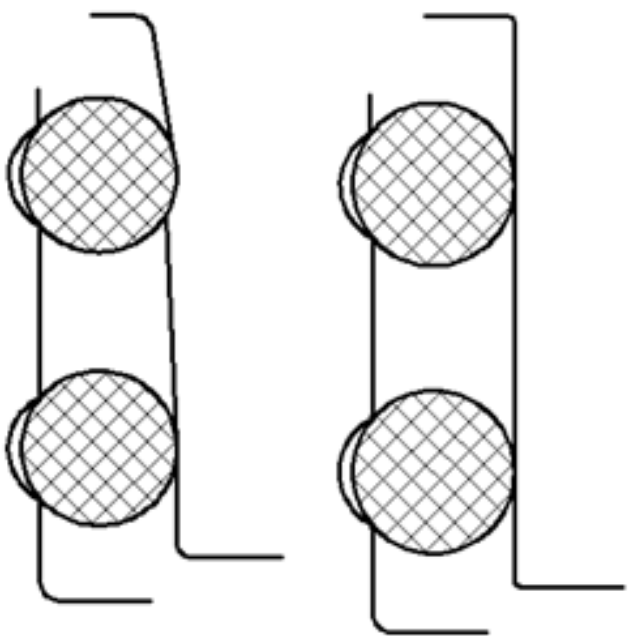

(a) Improve before sealing structure (b) The improved seal structure

Figure 4: Structure contrast figure before and after improvement

\subsection{Different back structural simulation analysis}

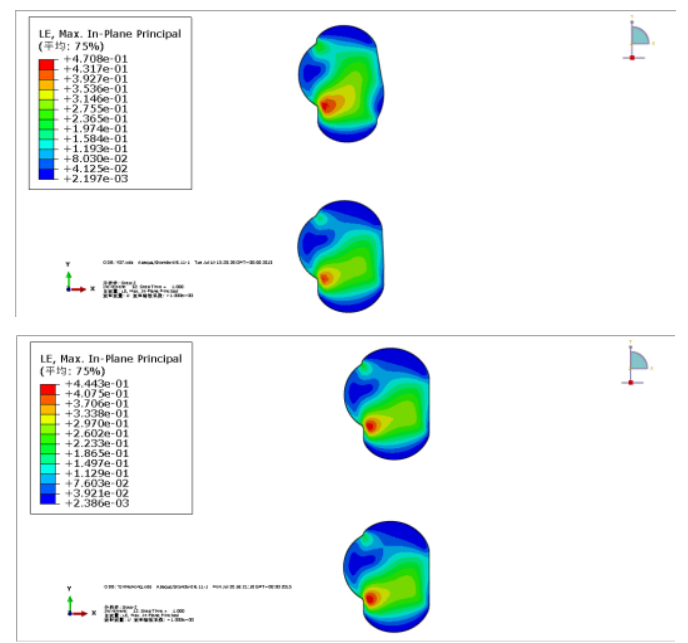

(a) Improve before strain diagram (b)The improved strain diagram

Figure 5: Strain contrast figure before and after improvement
The results showed that: (1) Straight cone hole makes the rubber ring strain distribution is consistent, is advantageous to the two rubber circle of life. (2) The maximum strain was occurred under the rubber ring and journal slot contour contact place, because here have sharp corners structure caused by stress concentration area, shows that they have taken place in the larger compression deformation. (3) Straight cone hole is beneficial to reduce the deformation degree of two rubber ring, the strain values from 0.47087 to 0.4443 .
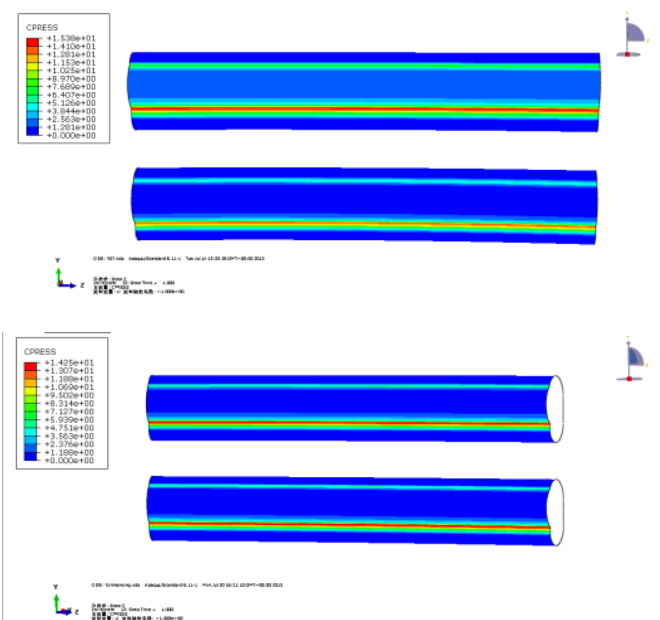

(a) Improve before contact pressure (b) The improved contact pressure

Figure 6: Contrast figure of contact pressure before and after improvement

The results showed that: (1) the prototype structure and rubber ring of the contact pressure distribution, and the improved uniformity, the distribution of contact pressure contact pressure is concentrated. (2) the upper and lower aprons sealing pressure maximum sealing pressure is greater than normal work requirements, (as shown in figure 6 a). Its value is $15.38 \mathrm{Mpa}$, and drill bit bearing seal pressure for 5 -6 Mpa commonly can ensure the reliability of the seal. Excessive seal pressure too much rubber ring to the compression ratio for the sealing surface sealing pressure as needed. This greatly affect the performance of the rubber ring, reduce its flexibility and aging resistance, and thus the service life of rubber ring. (3) straight cone inner hole can lower the contact pressure of two rubber ring and makes the rubber ring contact pressure distribution uniform.

The compression rate: Improved two rubber ring compression rate was $21.68 \%$, the compression ratio is lower than the prototype structure (on the rubber ring, rubber ring under $25.01 \%$ and $21.74 \%$ ).

Through the above simulation analysis showed that:

(1) Straight cone hole makes the rubber ring of Mises stress, strain and contact pressure distribution is consistent, to achieve two rubber circle of life.

Two rubber ring (2) straight cone hole is beneficial to reduce the Mises stress, strain and contact pressure, reduce the compression ratio of rubber ring, both rubber ring compression rate is greater than the normal work of the 


\section{International Journal of Science and Research (IJSR) \\ ISSN (Online): 2319-7064}

Index Copernicus Value (2013): 6.14 | Impact Factor (2015): 6.391

rubber ring compression rates $(10 \%-15 \%)$, still need to do

further improvement.

\subsection{Journal open different slot structure simulation analysis}

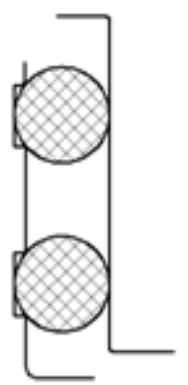

Rectangular

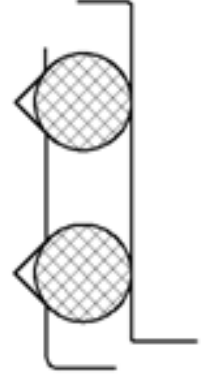

V

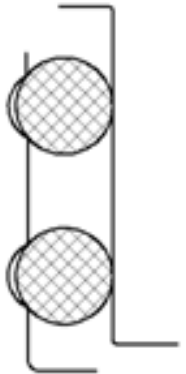

Arc-shaped Up rectangular down v Up v down rectangular

Figure 6: seven different journals open slot structure

The simulation results
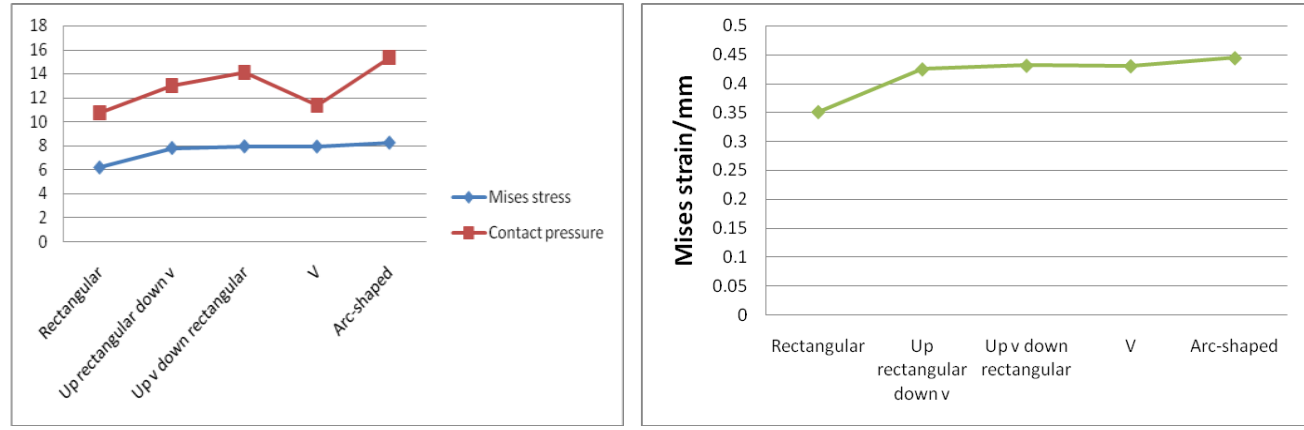

(a) Mises stress, contact pressure (Mpa) (b) strain

Figure 7: different slot structure of Mises stress, strain and contact pressure diagram

The results showed that:

(1)No matter how journal trough structure overall stress distribution trend of two rubber ring is the same. Both rubber ring large deformation happened along the groove structure, explain the main support structure of rubber ring. Is this part of the structure design determines the compression deformation of the rubber ring size. Torque type slot of Mises stress, contact pressure, Mises strain value is the lowest, highest circular arc form.

(2) Two rubber ring at the slit chamfering and the large deformation, the stress and strain, contact pressures are the biggest, because the structure has sharp corners is the stress concentration area, indicating that this $\mathrm{O}$ type rubber ring prone to damage. At this point there are two possible outcomes, is a kind of seal failure directly, the other is a sealed temporarily not failure, but the sealing ring is damaged, continue to work when the failure. Maximum compressive stress along the normal direction of the boundary extension and gradually decreases, so the main compression deformation occurred near the center. Due to the large compressive stress at sharp corners so can produce tensile stress, tensile stress along the groove structure expands gradually, with the increase of compression deformation and tensile stress will become bigger.

(3) Different slot structure of compression ratio is greater than the normal work of the rubber ring compression ratio, the maximum torque type compression ratio $21.68 \%$,
$\mathrm{V}$-shaped minimum is $20.54 \%$, but the difference is not big.

(4)Better rectangular relative to other type groove structure, use a combination of different shape groove, the rectangular on the combination of $\mathrm{V}$ groove under stress is lower than the $\mathrm{V}$ groove moment combination. rectangular type slot contact pressure is higher than meet the pressure value of normal work, the greater the pressure value, the more powerful the wear, under the condition of guarantee effective sealing pressure should be as far as possible to reduce the contact pressure, so we deal with rectangular type slot for further improvement.

\subsection{Different chamfering structure}

Improving the rectangular rabbet chamfering structure, reduce the strain and contact pressure of rubber ring, the strain value, contact pressure under the condition of the guarantee seal to reduce as much as possible

Finite element model are as follows: 


\section{International Journal of Science and Research (IJSR) \\ ISSN (Online): 2319-7064}

Index Copernicus Value (2013): 6.14 | Impact Factor (2015): 6.391

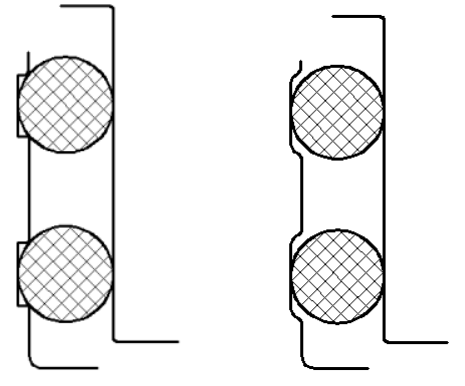

(a)Chamfering 0.2 (b) the double chamfer of 0.5

Figure 8: Different chamfering structure

The results of simulation analysis:

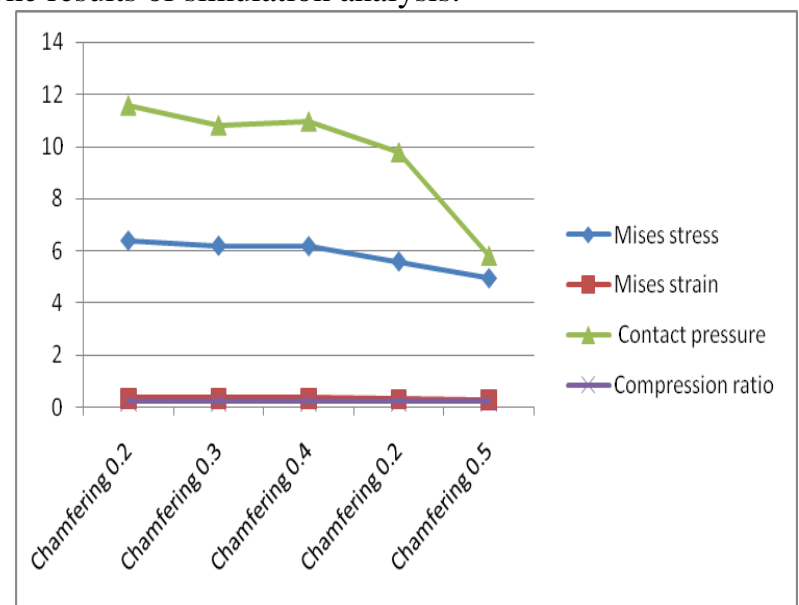

Figure 9: Different chamfering structure comparison

The results showed that:

chart

1) With the increase of chamfering radius, rubber ring of Mises stress, strain and contact pressure is reduced, increase the chamfering radius, can reduce the wear of rubber ring, degree of deformation.

2) Pour double fillet, rubber ring of Mises stress, strain and contact pressure achieves the lowest, in reducing the rubber ring of Mises stress and strain at the same time, the maximum contact pressure is $5.804 \mathrm{Mpa}$, satisfy the normal contact pressure seal.

3) Different slot structure, the rubber ring minimum average compression ratio of compression ratio is $19.84 \%$, is still greater than the range of normal compression, but the change is not big, too much compression ratio, will add to the rubber ring aging and wear and tear, shorten the life.

Therefore, double rounded slot structure can meet the sealing pressure of rubber ring, but for improving the compression ratio in rubber ring.

Based on the results: preliminary choose double rounded slot structure.

4.5 Different rubber ring cross section shape of the simulation analysis
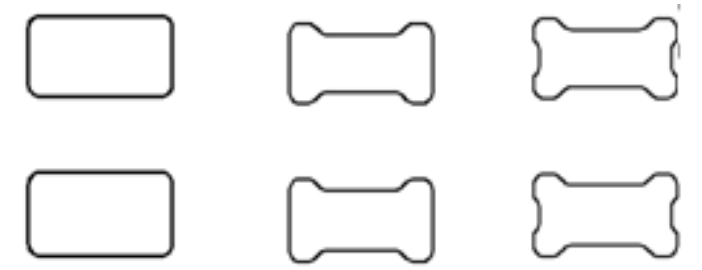

Rectangular section Single section

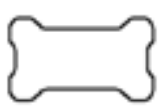

$\mathrm{X}$ section
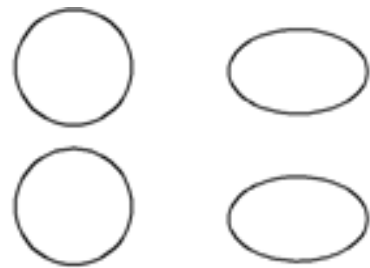

O section

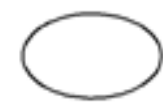

Elliptical section

Figure 10: different cross section shape
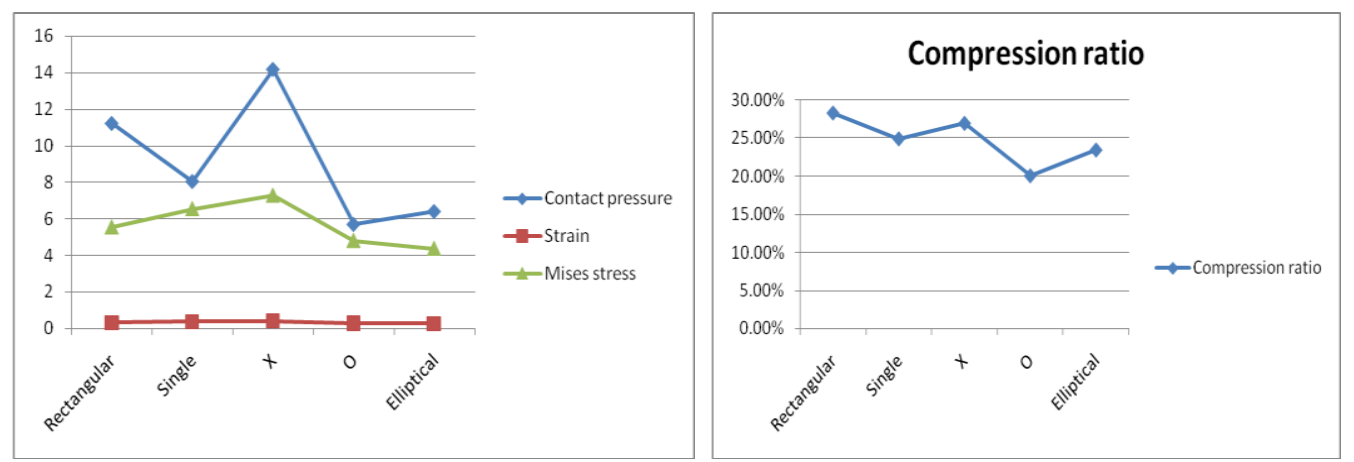

Figure 11: Different cross section shape of Mises stress and strain, the maximum contact pressure and compression ratio

Based on the simulation results show that:

1) Different cross section shape of rubber ring strain values were similar, that cross section shape of the rubber ring for a little effects on the strain of the rubber ring.

2) Different cross section shape of rubber ring contact pressure is large, the type $\mathrm{O}$ rubber ring largest minimum sealing pressure, its value is $5.688 \mathrm{Mpa}$, can satisfy the normal contact pressure seal.
3) Different cross section shape of rubber ring compression rate change is not big, but the minimum compression ratio is greater than normal rubber ring compression ratio $(10 \%-15 \%)$.

\section{Conclusion}

1)Through the simulation analysis software of ABAQUS

Volume 5 Issue 6, June 2016 www.ijsr.net 


\section{International Journal of Science and Research (IJSR) \\ ISSN (Online): 2319-7064}

Index Copernicus Value (2013): 6.14 | Impact Factor (2015): 6.391

analysis different inner pore structure on the stress influence of the rubber ring, can draw inner pore structure decided two rubber ring and so on life design.

2)Different journal and slot structure and chamfering had a greater influence on the contact pressure of rubber ring, it is concluded that the optimal rectangular groove structure and chamfering lower aging and wear of rubber ring, reduce the stress concentration phenomenon of rubber ring, so as to improve the service life of rubber ring.

3)Different cross section shape of rubber ring stress contrast, has a guiding role for guiding design.

\section{Reference}

[1] Z. Wang, Q. Peng, M. Sue, S. Qi .Failure analysis of rock bit bearing system [J]. Journal of southwest petroleum institute, 1987 (03).

[2] $\mathrm{Xu}$ Sheng. $\mathrm{O}$ ring and its mold [J]. oil drilling machinery,1985 (06).

[3] Ziyu Wang.failure analysis of rock bit bearing system [J]. Journal of southwest petroleum institute. 1987, 9 (3) : $72-86$.

[4] X. Zhou, Z. Wang, J. Zhang. Typical of the cone bit bearing seal structure and the main influencing factor of the failure [J]. Journal of southwest petroleum institute, in September, 1990, 1-4.

[5] Fafen Xing. Cone bit bearing double sealing system: China, CN102587835A [P]. 2012-07-18.

[6] X. Xiao, B. Chen,C. Sun, Y. Liu, Y. Xu. High speed roller bit bearing double metal seal structure optimization analysis $[\mathrm{J}]$. Journal of petroleum machinery, 2014 (10). 